\title{
The impacts of different façade types on energy use in residential buildings
}

\author{
Serik Tokbolat ${ }^{1, *}$, Yelaman Naizabekov ${ }^{1}$, and Stefano Mariani ${ }^{2}$ \\ Dept. of Civil and Environmental Engineering, Nazarbayev University, 53 Kabanbay Batyr Ave, Nur-Sultan, 010000, Kazakhstan \\ Dept. of Civil and Environmental Engineering, Politecnico di Milano, 32 Piazza Leonardo da Vinci, 20133 Milano, Italy
}

\begin{abstract}
Globally, buildings are responsible for a significant share in energy consumption and greenhouse gas emissions profiles. Various attempts are undertaken to increase the energy efficiency of buildings and reduce their environmental impact. In semi-continental climate conditions with very hot summers and extremely cold winters, buildings should be carefully designed to ensure efficient harnessing of solar energy and reducing energy loss due to poor insulation and inappropriate use of materials. Amidst the fast development of the construction industry, different façade systems are used in Kazakhstan. In several cases, the choice of the façade materials is defined not by performance but rather by economic aspects and physical appearance. This project aimed to investigate various types of façades adopted in the construction of residential buildings and assess their performance in terms of their impact on buildings' energy consumption. The preliminary results indicate that there are five main types of façades widely used. Five different models were therefore built using energy simulation software and the respective energy consumption data were estimated. The results testify that buildings with brickwork (clay bricks) and stonework (travertine) façades were more energy efficient than those with brickwork (silica bricks), aluminum composite panels and decorated plaster façades.
\end{abstract}

\section{Introduction}

Buildings account for a significant share of the global energy consumption and greenhouse gas emissions (GHG). They therefore cause notable impact on resources scarcity and the climate change process [1]. This implies that the role of buildings' energy efficiency is of utmost importance and needs to be addressed. At present, various construction activities have some sort of sustainability targets, which make buildings "greener" or at least aim to decrease the amount of energy used during manufacturing or operational stages [2].

The building envelope, in general, and façade, in particular, is an important feature in terms of energy use in residential buildings. Efficient design of building envelope and façade can help in optimizing the building energy consumption which thereby will lead to the reduction in GHG emissions [3]. There are different types of façade systems used worldwide. According to the practice, each type has its own advantages and disadvantages depending on the locality of the building. A number of factors such as climate conditions, soil, economic aspects, and others influence the choice of the appropriate material or façade system type [4].

According to the conducted literature review, there are five general types of façade materials used. These materials can be used for cladding or can be attached to the surface of the building by means of various technologies. Depending on the materials used for external wall construction, façade component materials can perform different functions, including the most important one to create insulation to the building, and thus reduce energy consumption. The ultimate purpose of each façade system used defines the choice of materials adopted in constructing the façade, their quality as well as the functionality of the façade in general. Aspects such as ground quality, weather conditions, climate of the locality, economic aspects affect the final solution [1]. The aim of this study is to consider the residential building stock of Kazakhstan, identify main façade types and materials used to build them, and validate the findings of the literature review. Further, it is aimed to build simulation models to analyze the efficiency of such façade types with different sets of materials used on the overall energy use. Application of energy simulation tools such as, for example, EnergyPlus is considered as one of the ways to analyze the energy consumption. Assessing different types of materials for separate simulations will provide insights which will help to make conclusions regarding specific façade types.

\section{Methodology}

One of the main objectives of this research is to analyse the energy performance of the residential buildings with different façade types. This has been done

\footnotetext{
Corresponding author: stokblat@gmail.com
} 
by creating building models and using energy simulation tools. This study selected a typical model building located in Nur-Sultan city, Kazakhstan. Specific climate conditions and other parameters related to wind, solar irradiation and precipitations were considered via the software's library database. The steps undertaken by the selected research methodology are listed in the following. The materials to be described in Section 3 were identified by (1) physical observations in NurSultan city by the authors and (2) a literature review that confirmed the adoption of such façade and materials types in a wider international context. Further, (3) the identified façade types with the respective materials were adopted in the model. This means that five different models with different façade types were built and simulated. The final step (4) was related to performing the analysis to identify the energy use data and lead to consequent conclusions.

At present, there are several softwares that can perform energy performance analysis of a building such as, for example, DesignBuilder, TRNSYS, ICE IDA, etc. [5]. Based on the results of simulations, sufficient energy data can be collected and used for further application and analysis. Each of the mentioned software tools gives enough information about energy consumption of the model, but issues might be encountered due to the complexities in using them. Compared to other tools, usability of DesignBuilder is higher among engineers and architects due to its integration with SketchUp and OpenStudio packages [1].

In Kazakhstan's reality, building facades are selected based on purely economic considerations; adopting the aforementioned methodology based on energy performance simulation tools to compare various façade materials and their impact on buildings' energy consumption, can be considered as novel. This methodology then allows to select the optimal façade solution to address the energy deficit issue, as well as to make informed decisions by building designers.

\section{Data collected}

There are five main types of façade of residential buildings which were identified both by personal observations in Nur-Sultan city and literature review [6]:

- Clay brick

- $\quad$ Stonework (travertine)

- $\quad$ Silica brick

- Aluminum composite panel

- Decorated plaster

Each of these façade types has its own features and behaves differently, based on the environment in which they are used. Other building categories were not considered, due to their limited use in the residential sector.

Clay brick, shown in Figure 1, is one of the oldest sustainable construction building materials. It is a strong construction product which does not require significant maintenance. It can offer a long-term effectiveness and can be recycled at the end of its life-cycle. Among some of the key properties is the heat resistance, which is very instrumental in reducing energy consumption of the building [7].

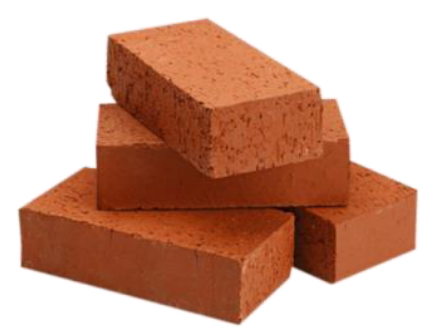

Fig. 1. Clay bricks [7].

Stonework (travertine), shown in Fig. 2, is a type of natural stone which was made by hot springs. It is formed due to the fast precipitation of calcium carbonate and mostly comes in light colors. It can be easily processed, which effectively decreases the amount of work to be done at the construction site [8].

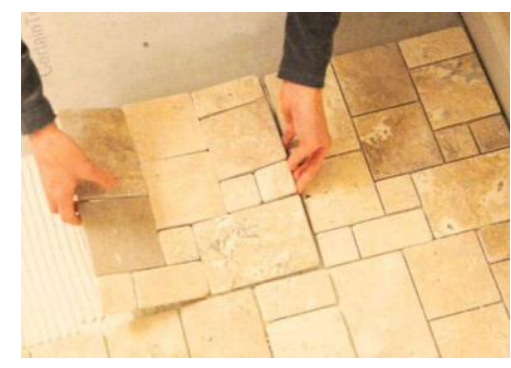

Fig. 2. Travertine [8].

Silica brick is shown in Error! Reference source not found.. It is an acid refractory material that has a good ability to resist an acid slag. It mostly consists of silicon dioxide $\left(\mathrm{SiO}_{2}\right)$. It has the property to keep its volume stable despite the high temperatures during summertime. Good air tightness of silica brick helps the building to avoid inward or outward air leakage [9].

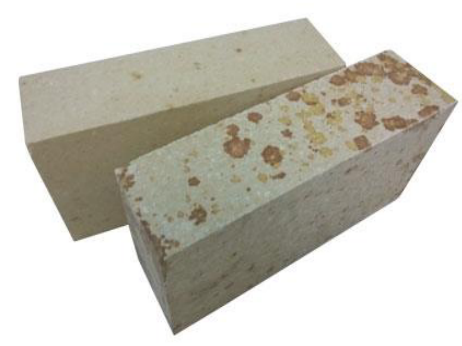

Fig. 3. Silica bricks [9].

Aluminum composite panel, shown in Fig. 4, is a lightweight panel made of aluminum which ideally suits for building façades. The versatility and formability of this type of façade makes it easy to maintain and improve aesthetic view of the building. Moreover, 
aluminum composite panels are cost effective with respect to similar products such as high pressure laminates [10].

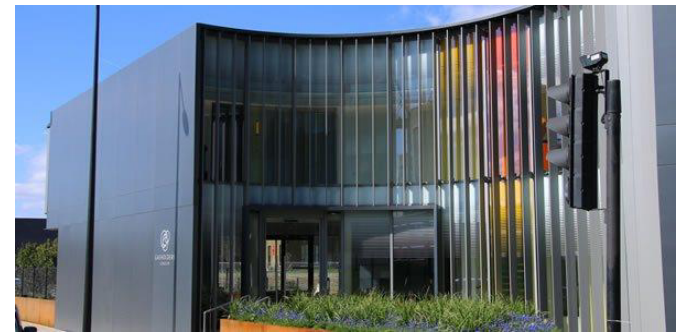

Fig. 4. Aluminium panels [10].

Decorated plaster, shown in Error! Reference source not found., is a plaster used as a façade of buildings and made of air lime mortar. The choice of such plaster is usually defined by its variability in colors (can be brown, yellow, green, white, red). In most of the cases, the reason for using such façades is decoration purposes of the building [11].

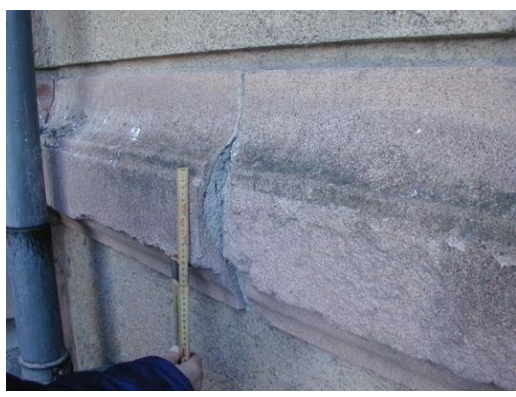

Fig. 5. Decorated plaster [11].

\section{Results and Discussion}

A multifamily residential building with 3 floors and 6 rooms at each floor was constructed, as shown in Figure 6. The building was simulated on DesignBuilder software.

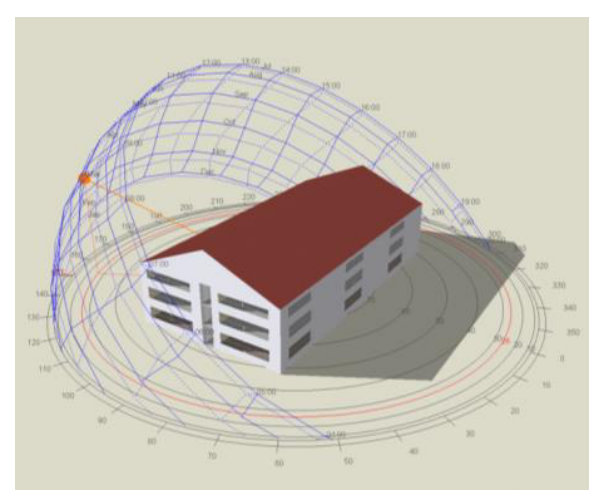

Fig. 6. Multifamily residential building.

The building model was built using the library database of the DesignBuilder software. Most of the building components were pre-selected from the library and were chosen in accordance to the existing construction standards and norms of Kazakhstan. During the model development, it was assumed that it will have the same external wall for all the considered scenarios but with five distinct materials (namely clay brick, travertine, silica brick, aluminium composite panel and air lime mortar); hence, different properties were used for the façade. Other three materials considered in the analyses, besides the outermost layer, were extruded polystyrene, concrete block and gypsum plastering. The properties of the five façade materials are gathered in Table 1. The specific geometry of the building model was chosen in accordance to typical residential building design met in Kazakhstan. Since the same model is used for all the five façade types, there are no geometry-related differences among them.

Table 1. Façade materials properties.

\begin{tabular}{|c|c|c|c|c|c|}
\hline Properties & $\begin{array}{l}\text { Clay } \\
\text { brick }\end{array}$ & $\begin{array}{l}\text { Traver } \\
\text { tine }\end{array}$ & $\begin{array}{c}\text { Silica } \\
\text { brick }\end{array}$ & $\begin{array}{c}\text { Alumi } \\
\text { nium }\end{array}$ & $\begin{array}{c}\text { Air } \\
\text { lime }\end{array}$ \\
\hline $\begin{array}{c}\text { Thermal } \\
\text { conductivity } \\
(\mathrm{W} / \mathrm{m}-\mathrm{K})\end{array}$ & 0.84 & 2.17 & 1.67 & 230 & 0.4 \\
\hline $\begin{array}{c}\text { Specific Heat } \\
\text { capacity (J/kg- } \\
\mathrm{K})\end{array}$ & 800 & 1090 & 753 & 880 & 1000 \\
\hline $\begin{array}{c}\text { Density } \\
\left(\mathrm{kg} / \mathrm{m}^{3}\right)\end{array}$ & 1700 & 2710 & 1800 & 2700 & 1000 \\
\hline
\end{tabular}

Energy consumption simulations were conducted for each type of façade material and outcomes can be found in Table 2. Each model was tested to assess the energy use for heating and cooling, during a period of one year. Although the heating and cooling energy consumption varies according to the seasons for each type of façade, this study made conclusions based on the total amount of energy used. According to the results obtained, it can be observed that the building model constructed with the outermost layer made of clay brick consumes the lowest amount of energy - $69154.12 \mathrm{kWh}$ per year - whereas the highest result can be observed in the case of the building façade with the outermost layer being made of aluminum composite - 99109.06 kWh annually. This result seems quite reasonable, with the total energy consumption relevant to clay bricks being almost $30 \%$ (thirty percent) smallerthan when aluminum was used. It shows that the material properties, specifically the conductivity, play a critical role. High level of heat loss due to a high level of conductivity, leads to higher amounts of energy used during cold seasons as can be seen in Figure 7.

Generally, based on the data obtained with the DesignBuilder software it can be assessed how the building walls constructed with different façade materials affect the overall results. The sum of heating and cooling electricity gives the total energy consumed by the corresponding envelope type. In Table 2 , it can be seen that buildings with clay bricks and travertine respectively use $69154.12 \mathrm{kWh}$ and $76564.2 \mathrm{kWh}$. These numbers increase as the material changes to silica bricks, aluminium panels or decorated plaster. The reason of such a big difference in the energy consumption of the different solutions is the set of physical properties of each material, especially in terms of thermal conductivity, density and specific heat. 


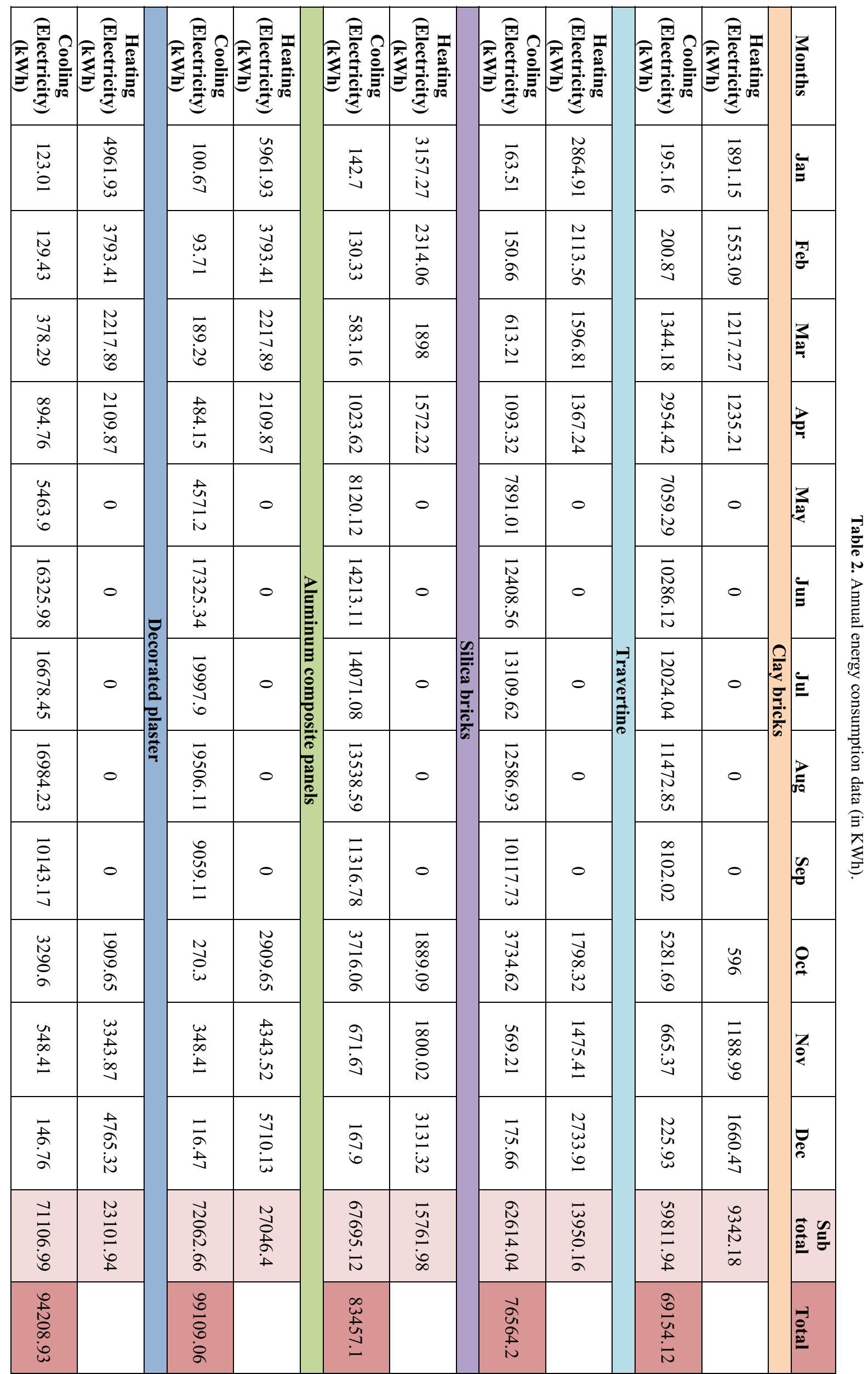


An increase in the conductivity level leads to more energy consumption. Moreover, each of the tested materials has a different thickness level, which is also a key factor to obtain such scattered results. For example, clay bricks, travertine and silica bricks have a thickness of 10-20 cm, whereas the thicknesses of aluminum panels and decorated panels are significantly smaller. The thickness difference can be most likely explained from the economic point of view and by quality considerations.

Lower quality houses are usually built with the lower budgets. Having cheaper option for the façade is a good way to reduce the materials costs. For instance, aluminum panels with thickness of $10 \mathrm{~cm}$ are not profitable to use. In most of the cases, panels and plasters have the thickness of 1-2 $\mathrm{cm}$. The costs of the five considered materials per one square meter, according to the local market situation, are provided in Table 3 [12]. Values in it provide both the cost of the material itself and the labour cost. It can be observed that, for example, clay brick is the most expensive solution for the façade, for both material and labour costs.

Table 3. Cost of facade materials and labour (per sq.m.)

\begin{tabular}{|l|c|c|c|c|c|}
\hline Cost (in USD) & $\begin{array}{l}\text { Clay } \\
\text { brick }\end{array}$ & $\begin{array}{l}\text { Traver } \\
\text { tine }\end{array}$ & $\begin{array}{c}\text { Silica } \\
\text { brick }\end{array}$ & $\begin{array}{c}\text { Alumi } \\
\text { nium }\end{array}$ & $\begin{array}{c}\text { Air } \\
\text { lime }\end{array}$ \\
\hline Materials & 25 & 8.5 & 8 & 12 & 6.6 \\
\hline Labour & 20.5 & 18.4 & 20.5 & 7.3 & 12 \\
\hline Total & 45.5 & 26.9 & 28.5 & 19.3 & 18.6 \\
\hline
\end{tabular}

In terms of energy consumption compared to clay bricks, (the most efficient solution) the amounts are respectively greater by $10 \%, 18 \%, 31 \%$ and $27 \%$ for travertine, silica bricks, aluminum panels and decorated plasters. A similar tendency can be observed in terms of the total cost of the façade per square meter, as shown in Table 3. The clay brick is more expensive than travertine, silica brick, aluminum panels and decorated plasters by $41 \%$, $38 \%, 58 \%$ and $60 \%$, respectively. The relevant trends can be observed in the graphs of Figure 7 and Figure 8 .

From the provided data, it can be stated that clay bricks and travertine are close to optimal in terms of energy use levels, whereas the remaining three materials represent the less desirable options. These three latter options tend to be instead used, due to their relatively lower material and labor costs. Given the relatively low energy prices in Kazakhstan, the difference between the most and least energy efficient façades (clay bricks and aluminum panels) is $31 \%$ in terms of energy use, and $60 \%$ in terms of cost. Solely from the economic point of view, a façade made of aluminum panels is the most optimal solution. However, disadvantages of this façade type are not only the high energy use, but also the poor insulation which can cause "cold walls" effects due to thermal bridges between the panels. Another problem associated with this façade type is the high level of flammability of the material. Kazakhstan's building sector experienced a number of serious fires over the last decade, see e.g. [13]. All of these issues cannot be observed in the case of brickwork (clay bricks). Therefore, decision making stakeholders should take into account aspects such as, among others, energy consumption, safety, costs and aesthetic features. From the point of view of overall sustainability and climate change impacts, it is suggested to pay more attention to energy use aspects, which also indirectly affect the thermal comfort inside the building, especially in the extreme climate conditions.

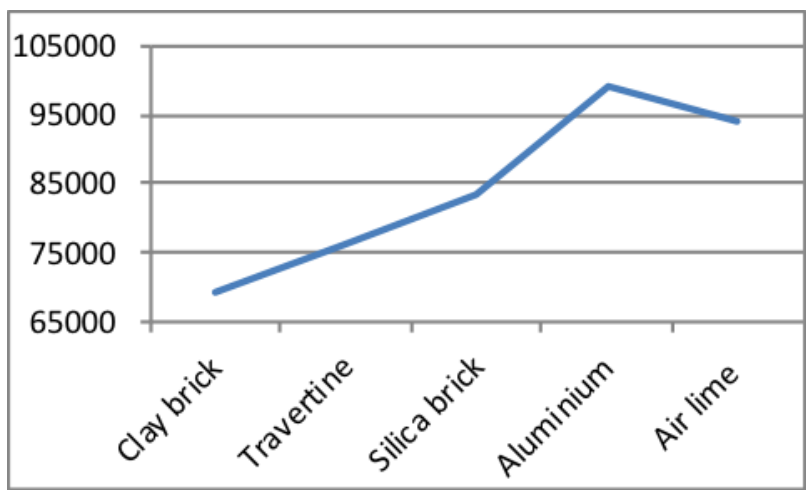

Fig. 7. Energy use vs façade materials (in $\mathrm{kWh} /$ year)

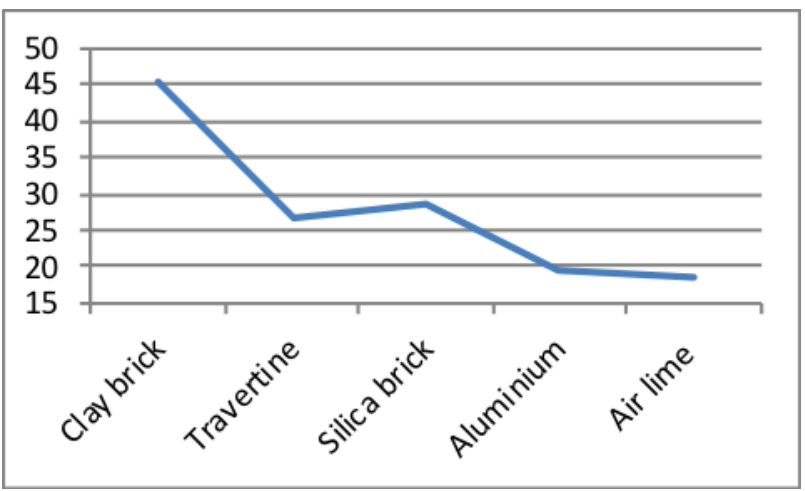

Fig. 8. Cost of façade materials and labor (in USD/sq.m.)

\section{Conclusions}

In this study, five different residential building façade types were simulated on the DesignBuilder software with the built-in EnergyPlus platform. Each of the façade types turned out to be characterized by its distinct material properties as well as material and labour costs. According to the results obtained, it can be concluded that clay bricks and travertine are the most appropriate materials to use in residential buildings in Nur-Sultan city. There is a number of factors that were taken into account to make such a conclusion. One and the most significant one is the climate of the Nur-Sultan city. As a result, the weather conditions of Nur-Sultan are not appropriate to use silica bricks, aluminium panels and decorated plaster. The factors such as wind, snow load, extremely low and high temperatures during winter and summer, are key factors considered to choose travertine 
or clay bricks. The study confirmed this argument by means of accurate energy consumption data. It should be also noted that the costs of the different façades differed significantly: while the façade options like silica bricks, aluminium composite panels and decorated plaster were found to be cheaper than clay bricks and travertine, their behaviour in terms of energy use was the opposite. Overall, clay bricks and travertine façades resulted to be more energy efficient than the other formerly mentioned materials.

\section{References}

1. M. T. Kahsay, G. Bitsuamlak, and F. Tariku. Num. An. Conv. H. Trans. Coef. Build. F. Journal of Building Physics 42 (6): $727-749$ (2019)

2. S. Atti, S. Garat, and M. Cools. Dev. Val. Sur. W. I. Asses. Occ. Off. Build. Adap. F. Building and Environment 157: 268-276

3. Krstić-Furundžić A., Kosorić V. Imp. En. Per. Ex. Build. App. Sol. Th. Sys. (2009)

4. J. Vitkala, F. H. R. Build. Arch. Str. Eng. Accessed October 13, 2019

5. A. Gagliano, S. Aneli, and F. Nocera. A. Per. Build. Sol. Th. F. Dom. Hot Wat Prod. Renewable Energy 142: 511-526 (2019)

6. T. Baran, Mete K. Th. Ins. Per. Th. Cond. Ev. Nat. St. Inf. Ther. (2014)

7. Masonry, Modern. Clay bricks." https://www.modernmasonry.co.uk/MMA/Resources Clay-Bricks.aspx. (n.d.)

8. S. Stone, G Trav. T. Pr. Co. Accessed October 22, 2019. https://sefastone.com/blogs/s/travertine-tilepros-and-cons. (2016)

9. Materials, Refractory. Si. Br. Accessed October 22, 2019. https://refractoriesmaterials.com/silica-bricks/. (n.d.)

10. Valkan, Al. Comp. Pan. Accessed October 11, 2019. https://valcan.co.uk/information/aluminiumcomposite-panels/. (n.d.)

11. V. Soren, Cons. Pl. Arch. F. Work. Tech. Rep. Met. Accessed October 23, 2019. https://www.bygningsbevaring.dk/uploads/files/engli sh/conservation plaster.pdf. (2008)

12. Flagma, Kirp. K1. Accessed January 10, 2019. https://flagma.kz/s1/kirpichnaya-kladka-so1383600166-1.html

13. Walking, Almaty, Al. F. Accessed January 10, 2019. http://www.walkingalmaty.com/aluminumfacades.html (n.d.)

14. CompareRocks, Prop. Trav. Accessed October 18, 2019. https://rocks.comparenature.com/en/propertiesof-travertine/model-22-6. (n.d.)

15. Greenspec, Th. M. Accessed October 19, 2019. http://www.greenspec.co.uk/building-design/thermalmass/. (n.d.)

16. A. Krstic-Furundzic, M. Vujosevic, and A. Petrovski.. En. Env. Perf. Off. Build. F. Sc. Energy 183: 437-447. https://doi.org/10.1016/j.energy.2019.05.231. (2019)

17. J. Oh, C. Koo, T. Hong, and S. H. Cha. Int. Mod. Est. Tech. Econ. Perf. Dist. Sol. Gen. Sys. Build. F. Applied Energy 228: 1071-1090 (2019)

18. C. Planas, E. Cuerva, and P. Alavedra. Eff. Typ. F. O. En. Perf. Off. Build. Repr. Cit. Barca. Ain Shams Engineering Journal 9 (4): 3325-3334 (2018) 